\title{
Comparative analysis of Land Surface Temperature model inversion by multiple methods
}

\author{
Liu Na-na ${ }^{1}$, Zhou Yang ${ }^{1 *}$ \\ ${ }^{1}$ Chongqing Real Estate College, Chongqing 401331, China
}

\begin{abstract}
Land surface temperature is the surface of the earth's energy change and the exchange process, which is an important index for a lot of scientific research, it can be obtained in a variety of ways , combining with scientific research workers at home and abroad for many years, the land surface temperature acquisition methods are summarized, four land surface temperature methods are introduced and their characteristics are analyzed.
\end{abstract}

\section{The introduction}

Land surface temperature(LST) refers to the result that the heat energy of the sun is radiated to the ground, part of it is reflected, part of it is absorbed by the ground, so that the ground generates heat and avoids the temperature change of the earth after measurement.Land Surface temperature is a very important parameter in the study of geographical surface physical systems on regional and global scales, and it is a comprehensive expression of the energy transformation of the interaction between land and atmosphere [1-4]. Land surface temperature has a wide range of applications in many basic scientific research and fields, such as regional climate change, ecological environment, thermal inertia and soil moisture, hydrological balance, and agricultural applications ${ }^{[5-9]}$. Therefore, how to accurately, save time and effort to obtain land surface temperature has become the research content of researchers in recent years.

With the continuous progress of scientific and technological means, the land surface temperature acquisition method is also constantly developing, from the original meteorological station to the use of remote sensing images, as well as the use of microwave signal inversion, from man-made measurements to numerical models, have made great progress and improvement. Different methods of land surface temperature acquisition are described in this paper.

\section{The method of obtaining the land surface temperature based on the observation of meteorological stations.}

The method is based on the historical meteorological data of meteorological stations. The meteorological station adopts the real-time data recorded by observation stations or mobile observation stations, and the measured database is the atmospheric temperature near the surface. This method can obtain the temperature data of timecontinuous observation stations in the city and in the suburbs, so as to obtain their differences ${ }^{[10]}$. Kriging spatial interpolation method can also be used to draw a weather map of spatial continuous distribution ${ }^{[11]}$. The Kriging spatial interpolation formula is as follows:

$$
\hat{Z}\left(s_{0}\right)=\sum_{i=1}^{N} \lambda_{i} Z\left(s_{i}\right)
$$

In the formula:

$\mathrm{Z}\left(\mathrm{s}_{0}\right)$ - the i measured value at the ith position

$\lambda_{\mathrm{i}}$ - unknown weight of the measurement at position $\mathrm{i}$

$\mathrm{S}_{0}$ - predicted position

$\mathrm{N}$ - the number of measurements

Using meteorological sites to get the data recorded accurately in detail, but it takes a lot of manpower and material resources and financial resources, and the number of monitoring sites and distribution by the image of the terrain and the surrounding environment and limitation, which leads to uneven distribution of the site, not easy to form the continuous observation on the spatial data, spatial representation, not suitable for a wide range of area studies. This traditional monitoring method is usually used for regional temperature changes over the course of a day or seasonal changes over the course of a year. Many researchers have tried to study the urban heat island effect in this way.

\section{Numerical model analysis}

Numerical Model analysis is with the aid of a computer system, the mathematical Model was established based on the measured data and data analysis, the numerical

\footnotetext{
* Corresponding author: 545195968@qq.com
} 
Model is established by the WRF (Wearer Research and Forecast Model), This model can simulate local climate and geological conditions after processing highresolution urban information data $^{[12]}$. In addition, some researchers combined WRF with NCEP/NCAR reanalysis of meteorological data to simulate the thermal environment of cities and the change of land surface temperature with the factors of the underlying surface of cities, and confirmed that the change of land use for urbanization will increase the land surface temperature of furniture ${ }^{[13]}$.

This from the simple one dimensional numerical model to $2 \mathrm{~d}$ to $3 \mathrm{~d}$ mode, reduce a lot of manpower and material resources and financial resources in the measured consumption, the numerical model is based on the ideal conditions, and higher requirements for resolution and accuracy, and can't completely simulate complicated factors of real environment, so the data obtained by this method has a certain reference.

\section{Land surface temperature inversion using remote sensing data}

The land surface temperature inversion principle of remote sensing data is based on the changes of the radiation values of different bands of the objects attached to the underlying surface of the city by the thermal infrared sensor, which can present the spatial form of continuous changes of the surface temperature at the same time point. In the 1960 s, foreign countries began to use satellite data of remote sensing technology to invert land surface temperature ${ }^{[14]}$. In 1984, Price used satellite data of the national oceanic and atmospheric research center of the United States to invert ocean surface temperature. Later, some foreign scholars used MODIS data and ASTER data to obtain the land surface temperature. In the 1980 s, China began to study the surface temperature ${ }^{[15]}$, and also used MODIS data to invert the land surface temperature of some cities ${ }^{[16]}$.

The commonly used remote sensing data sources include GOES, SEVIRI, AATSR, MODIS, AVHRR, ASTER, ATLAS, TM/ETM +, and the new Chinese satellite gaofen-1. Among them, AVHRR and MODIS are suitable for large-scale and wide-area studies ${ }^{[17]}$. Common land surface temperature inversion algorithms and applicable conditions are shown in the following table1 ${ }^{[18]}$.

Table 1. Comparison and application of surface temperature inversion using remote sensing data

\begin{tabular}{|c|c|c|c|}
\hline & $\begin{array}{c}\text { Atmospheric } \\
\text { correction } \\
\text { method }\end{array}$ & $\begin{array}{c}\text { Split window } \\
\text { algorithm }\end{array}$ & $\begin{array}{c}\text { Multichannel } \\
\text { algorithm }\end{array}$ \\
\hline $\begin{array}{l}\text { The } \\
\text { data } \\
\text { source }\end{array}$ & $\begin{array}{c}\text { Single sensor in } \\
\text { thermal infrared } \\
\text { band }\end{array}$ & $\begin{array}{l}\text { Two or mo-re } \\
\text { different chann- } \\
\text { els of remote } \\
\text { sensing satellite } \\
\text { data in ther-mal } \\
\text { infrared band }\end{array}$ & $\begin{array}{c}\text { There are many } \\
\text { thermal infrared } \\
\text { band data }\end{array}$ \\
\hline $\begin{array}{c}\text { Apply } \\
\text { satellite }\end{array}$ & $\begin{array}{l}\text { Landsat TM/- } \\
\text { ETM + /The } \\
\text { TIRS series of }\end{array}$ & $\begin{array}{c}\text { MOAA/AVHR } \\
\text { Terra- } \\
\text { Aqua/MODIS }\end{array}$ & $\begin{array}{c}\text { EOS-MODIS } \\
\text { ASTER }\end{array}$ \\
\hline
\end{tabular}

\begin{tabular}{|c|l|c|l|}
\hline & satellites & Lands-at8 & \\
\hline $\begin{array}{c}\text { Feature } \\
\text { s and } \\
\text { applicat } \\
\text { ions } \\
\text { input the impro- } \\
\text { ved parameters, } \\
\text { and the improv- } \\
\text { ed algorithm } \\
\text { puts forward the } \\
\text { simulation } \\
\text { parameters }\end{array}$ & $\begin{array}{c}\text { Eliminating } \\
\text { atmospheric } \\
\text { water content } \\
\text { image is } \\
\text { suitable for } \\
\text { ocean } \\
\text { temperature } \\
\text { inversion }\end{array}$ & $\begin{array}{l}\text { It is suitable for } \\
\text { data with mult- } \\
\text { iple thermal in- } \\
\text { frared bands w- } \\
\text { ithout consider- } \\
\text { ing the data of } \\
\text { atmospheric } \\
\text { temperature and } \\
\text { water and gas } \\
\text { profile }\end{array}$ \\
\hline
\end{tabular}

The method of land surface temperature inversion using remote sensing technology can be used in sparsely populated and inaccessible areas. However, there are atmospheric and cloud conditions in the remote sensing image, and the inversion precision is easily affected by the image, which makes it difficult to obtain the land surface temperature in a long time series and a large scale.

\section{Land surface temperature inversion by passive microwave remote sensing}

Microwave remote sensing is the use of microwave equipment to detect and receive the electromagnetic radiation and scattering characteristics of the measured object in the microwave segment. As microwave band is located in the wavelength of $1 \mathrm{~m} \sim 1 \mathrm{~mm}$, in $0.3 \sim 300$ GHZ frequency electromagnetic range, compared with visible light, infrared remote sensing technology, microwave remote sensing technology has all-weather ability to work day and night, especially can penetrate the clouds, not easily affected by climate and sunshine, can penetrate the ability of detecting subsurface targets of vegetation, has a large military and economic significance. The common characteristic parameters of passive microwave remote sensor include frequency, width, incident Angle, transmitting time, transit time and instantaneous field of view.

However, due to the long wavelength of microwave, the spatial resolution of the image obtained by the microwave remote sensor is the same, so various coherent signal processing technologies need to be improved. At present, the application of passive microwave mainly focuses on the inversion of soil moisture ${ }^{[19-20]}$. The number of unknowns in surface temperature inversion using passive microwave is always greater than the number of equations, which makes it more difficult to study passive microwave surface temperature inversion. Currently, there is no universally recognized passive microwave surface temperature inversion method.

According to the different methods and means of establishing the algorithm, the existing passive microwave surface temperature inversion models can be roughly divided into empirical model, physical model and neural network mode ${ }^{[21-22]}$.

\subsection{Empirical model}


The empirical model is mainly used to invert the surface temperature by establishing the empirical relationship between the surface temperature of microwave satellite or some microwave index based on the surface temperature of satellite and the surface temperature ${ }^{[23]}$. There are two kinds of models: the empirical model based on the star temperature and the inversion algorithm based on the index. Many researchers at home and abroad use the inversion formula of surface temperature based on the empirical model component of the satellite bright temperature. The experimental results show that the precision of surface temperature inversion by these formulas is about $1.6 \sim 6 \mathrm{~K}$, and the precision is slightly different between day and night ${ }^{[24-27]}$. The empirical model algorithm is simple and easy to use, but the estimation accuracy of surface specific emissivity has great uncertainty, so the estimation of surface temperature also has certain errors.

\subsection{Physical model}

Physical model method based on star bright temperature and surface temperature of the linear relationship between the radiative transfer equation for physical basis, but this method is also more unknowns than equation of the total number of questions, so many domestic and foreign scholars have put forward to reduce the number of unknown or increase the number of equations method, are mainly based on the same frequency of different polarization ratio emissivity relations inversion algorithm, the inversion algorithm based on different frequency than radiation relations than radiation rate does not change with time, assuming that the inversion algorithm, based on the simplified radiative transfer equation inversion algorithm of three methods. Physical model inversion of surface temperature, has a clear physical meaning, its reaction precision is in commonly $2 \sim 4.9 \mathrm{~K}^{[28-29]}$,to be higher than empirical model, but this method needs other than bright temperature accident data as input data, the application is not convenient, even though some physical model does not need to input data, other than light temperature accidents but also need to be based on some assumptions to solve surface temperature, and the accuracy of the temperature is closely related to the stability of the hypothesis.

\subsection{Neural network model}

The mathematical method to simulate the actual human neural network is called neural network. Neural network has a wide and attractive prospect in the fields of system identification, pattern recognition and intelligent control. The model is a complex network system composed of a large number of simple processing units (called neurons) that are widely interconnected. It reflects many basic features of human brain function and is a highly complex nonlinear dynamic learning system. With the abilities of massively parallel, distributed storage and processing, self-organization, self-adaptation and self-study, neural network is especially suitable for the processing of imprecise and fuzzy information which needs to consider many factors and conditions at the same time.

In the 1990s, the multi-layer sensor neural network model was used to estimate soil temperature, soil moisture and vegetation water content, and the multilayer sensor neural network was trained by the database to establish the inversion model for surface temperature, and the result showed that the estimation accuracy reached $2 \mathrm{~K}^{[30]}$. The neural network model is a mathematical method, which is simple and feasible, but a representative training database is needed to obtain a relatively ideal inversion result, so the inversion accuracy of the trained database is relatively large.

\section{Conclusion}

Land surface temperature has been widely used in many basic scientific research and field application,it has certain correlation with natural disasters such as urban heat island effect, climate change, atmospheric $\mathrm{CO}_{2}$ concentration, and sunspot cycle length (SCL), Based on the research methods of domestic and foreign scholars in recent years, this paper summarized the four commonly used surface temperature methods, and elaborated and compared them. There are many methods to obtain the surface temperature, but how to improve the accuracy of the surface temperature is still an important problem for researchers.

\section{The acknowledgements}

I'd like to thank Chongqing education commission for approving my research project "Image research of urbanization on surface humid and thermal environment-a case study of Chongqing's nine districts", and I would also like to thank Chongqing Real Estate College for providing research fund support for this project,and the last thanks to the efforts of the team members, we believe that our project will get very good results.

Project source: Science and technology research plan of Chongqing education commission in 2018 youth project "Image research on the land surface temperature and humidity environment of urbanization -- a case study of the ninth district of Chongqing" (Project no. : KJQN201805204)

\section{Reference:}

1. Chen Y.Y., Duan S.B., Ren H.Z., et al. Algorithm development for land surface temperature retrieval:Application to Chinese Gaofen-5 data. Remote Sensing, 2017, 9: 161.

2. Fan X.W., Tang B.H., Wu H., et al. A three-channel algorithm for retrieving night-time land surface temperature from MODIS data under thin cirrus clouds. International Journal of Remote Sensing,2015, 36: 4836-4863.

3. Duan S.B., Li Z.L., Tang B.H., et al. Generation of a time-consistent land surface temperature product 
from MODIS data. Remote Sensing of Environment, 2014, 140: 339-349.

4. Anderson M C, Norman J M, Kustas W P, Houborg R, Starks P J and Agam N. 2008. A thermal-based remote sensing technique for routine mapping of land-surface carbon, water and energy fluxes from field to regional scales. Remote Sensing of Environment, 112(12): 4227-4241 [DOI: 10.1016/j.rse.2008.07.09]

5. Zhang T, Barry R G, Gilichinsky D et al. An ampil signal of climatic change in 50 temperature during the last century at Irkutsk, Russia [J]. Climate Change, 2001, 49:41-76.

6. Hansen J, Ruedy R, Sato M and Lo K. 2010. Global surface temperature change. Reviews of Geophysics, 48(4): G4004 [DOI: 10.1029/2010RG000345]

7. Zhao L., Lee X.H., Schultz N.M. A wedge strategy for mitigation of urban warming in future climate scenarios. Atmospheric Chemistry and Physics, 2017, 17: 9067-9080.

8. Kogan F.N. Operational space technology for global vegetation assessment. Bulletin of the American Meteorological Society, 2001, 82: 1949-1964.

9. Tarpley J.D. Monthly evapotranspiration from satellite and conventional meteorological observations. Journal of Climate, 2009, 7: 704-714.

10. Feng X.G. Remote sensing study on the evolution and genesis of urban heat island effect:. Xi 'an: shaanxi normal university, 2011.

11. Zhang J, Zhang X.P, wang xiaoyun, et al. Multiscale temperature analysis and heat island effect in Beijing [J]. Geography of arid region, 2010,33 (1) : 51-58.

12. Sun $y$, wang Y.W. numerical simulation of urban heat island and local circulation characteristics under complex terrain [J]. Chinese journal of atmospheric sciences, 2019, 42 (2) : 280-292.

13. Bao W.J. Spatiotemporal characteristics and evolution of urban heat island in Shanghai:. Shanghai: fudan university, 2010.

14. Bredehoeft J D, Papadopulos I S. Rates of vertical ground-water movement estimated from the Earth's thermal profile [J]. Water Resources Research, 1965, (2): $325-328$.

15. Tang C.C, Wang J.X, zhang jian. A preliminary method for predicting spring precipitation field by using surface temperature anomaly of $0.8 \mathrm{~m}$ in winter [J]. Plateau meteorology, 1987, 6 (3) : 244255.

16. Xie D.Y. Geothermal characteristics of northern tarim basin [J]. Journal of China university of geosciences, 1993, 18 (5) : 627-633.

17. Zeng Y, Huang W, Zhan F B, et al. Study on the urban heat island effects and its relationship with surface biophysical characteristics using MODIS imageries[J]. Geo-spatial Information Science, 2010, 13(1):1-7.
18. Becker, F. The impact of spectral emissivity on the measurement of land surface temperature from a satellite[J]. International Journal of Remote Sensing, 1987, 8(10):1509-1522.

19. Shi J., Jiang L., Zhang L., et al. Physically based estimation of bare-surface soil moisture with the passive radiometers. IEEE Transactions on Geoscience and Remote Sensing, 2006, 44: 31453153.

20. Gong R. Soil moisture active and passive detection satellite. Satellite applications, 2015, 81 .

21. Ermida S.L., Jiménez C., Prigent C., et al. Inversion of AMSR-E observations for land surface temperature estimation, Global comparison with infrared satellite temperature. Journal of Geophysical Research: Atmospheres, 2017.

22. Jia Y.Y, Li Z.L. Research progress of surface temperature inversion based on passive microwave remote sensing data. Advances in geosciences, 2006, 25:96-105.

23. Han X.Z. Research on passive microwave remote sensing inversion algorithm for surface temperature under clouds:. Chinese academy of agricultural sciences, 2018.

24. Zhou J., Dai F., Zhang X., et al. Developing a temporally land cover-based look-up table (TL-LUT) method for estimating land surface temperature based on AMSR-E data over the Chinese landmass.International Journal of Applied Earth Observations and Geoinformation, 2015, 34: 35-50.

25. Neale C.M.U., Mcfarland M.J., Chang K. Landsurface-type classification using microwave brightness temperatures from the Special Sensor Microwave/Imager. IEEE Transactions on Geoscience and Remote Sensing, 1990, 28: 829-838.

26. Li W.B, Zhu Y.J. SSM/I remote sensing of ground temperature in eastern China. Advances in natural science, 1998, 305-313.

27. Mao K.B, Shi J.C, Li Z.L et al. A physical statistical algorithm for surface temperature inversion based on passive microwave AMSRE data. Sci China, 2006, 36:1170-1176.

28. Mialon A., Royer A., Fily M., et al. Daily microwave-derived surface temperature over Canada/Alaska. Journal of Applied Meteorology and Climatology, 2008, 46: 591-604.

29. Guha A., Lakshmi V. Use of the scanning multichannel microwave radiometer (SMMR) to retrieve soil moisture and surface temperature over the central United States. IEEE Transactions on Geoscience and Remote Sensing 2004, 42: 14821494.

30. Zurk L.M., Davis D., Njoku E.G., et al. Inversion of parameters for semiarid regions by a neural network. IEEE International Geoscience and Remote Sensing Symposium, 1992, 2: 1075-1077. 